\title{
PREPORUKE BTS ZA AMBULANTNO LEČENJE PLUĆNE TROMBOEMBOLIJE
}

\author{
BTS RECOMMENDATIONS FOR OUTPATIENT TREATMENT OF PULMONARY EMBOLISM
}

\author{
Jadranka Vučićević Trobok, Sandra Peković, Aleksandar Bokan', Milica Mirić, Miroslav Ilić
}

\section{Sažetak}

Plućna tromboembolija (PE) je stratifikovana prema riziku smrtnosti na osnovu indeksa težine plućne tromboembolije (pulmonary embolism severity index, PESI) i modifikovanog i pojednostavljenog PESI (simplified pulmonary embolism severity index, sPESI) na mali, umeren $i$ visok rizik, odnosno mali $i$ visok rizik od rane smrtnosti. Bolesnici sa malim rizikom za rani mortalitet od PE prema SPESI skoru su kandidati za ambulantno lečenje. Preporuke Evropskog kardiološkog udruženja (European society of cardiology, ESC) od 2014. g. su da se prema PESI skoru bolesnici dele na pet klasa. Prema SPESI skoru visok rizik od rane smrtnosti (odnosno PESI klasa III,IV $i \mathrm{~V}$ ) imaju bolesnici sa sPESI $>1$ bod $i$ mortalitet se kreće oko 10,9\%. Dok mali rizik od rane smrtnosti obuhvata grupu PESI I i II, to su bolesnici prema pojednostavljenom sPESI sa 0 bodova i 30-odnevnom smrtnosću od 1\%.

Prema preporukama Britanskom torakalnom udruženju (British thoracic society, BTS) od $2018 \mathrm{~g}$. uključujući kriteriji za ambulantno lečenje PE su bolesnici PESI klasa I i II ili sPESI sa 0 bodova ili sa 0 bodova prema Hestia kriterijumima. Komorbiditeti imaju značajnu ulogu u proceni mogućnosti lečenja u ambulantnim uslovima. Procena stanja bolesnika i mogućnost krvarenja onemogućava ambulantni tretman. Socijalni momenat (nemogućnost nege u kućnim uslovima, bez telefonske komunikacije, bez adherence i komplijanse za lekove) takođe sprečava bezbedan tretman u kućnim uslovim. Kod bolesnika sa sPESI skorom 0, rizik od krvarenja nije potrebno procenjivati (stepen preporuke B).

Bolesnici sa PE koji su kandidati za ambulantni tretman se mogu observirati 24 časa u bolničkim uslovima, a potom otpustiti. Lečenje se preporučuje niskomolekularnim heparinom (low molecular weight heparin, LMWH) i dabigatranom, LMWH i edoksabanom, samo direktnim oralnim antikoagulansima (DOAK) apiksabanom ili rivaroksabanom (stepen preporuke A) ili LMWH $i$ antagonistima vitamina $K$. Ambulantno se mogu lečiti i bolesnici sa PE kao posledice maligniteta, atrijalne fibrilacije i srčane insuficijencije kod kojih je slučajno dijagnostikovana PE. Kod maligniteta se slučajno otkrije PE u sklopu praćenja efekta hemio-, radioterapije ili biološke terapije. Ambulantno lečenje PE smanjuje mogućnost infekcije, troškova lečenja i poboljšava kvalitet života.
\end{abstract}

Ključne reči: plućna tromboembolija, PESI skor, sPESI skor, ambulantno lečenje, LMWH, DOAK.

\section{Uvod}

Plućna tromboembolija (PE) je treća kardiovaskularna bolest, ukupne godišnje incidence u svetu 100 do 200 na 100.000 stanovnika. Mortalitet PE nakon mesec dana je 9 do $11 \%$, a nakon tri meseca 8,6 do $17 \%$ (1). Incidenca raste zbog produženog životnog veka i unapređenja tehnike i dijagnostičkih procedura. Analizom registara venskog tromboembolizma (VTE) proširena je lista riziko faktora, te se češće razmišlja o ovom oboljenju. Plućna tromboembolija je stratifikovana prema riziku smrtnosti na osnovu indeksa težine plućne tromeboembolije (pulmonary embolism severity index, PESI) i modifikovanog i pojednostavljenog PESI-a (simplified pulmonary embolism severity index, sPESI) na mali, srednji i visok rizik smrtnosti ili mali i veliki rizik. Bolesnici sa malim rizikom za mortalitet od plućne tromboembolije prema sPESI skoru su kandidati za ambulantno lečenje. Preporuke Evropskog kardiološkog udruženja (European society of cardiology, ESC) od 2014. g. su da se prema PESI skoru bolesnici dele na pet klasa. Na one sa visokim rizikom za mortalitet klasa V (mortalitet 24,5\%), srednji u koje spada klasa III i IV koji se pak deli na nizak i visok rizik mortaliteta od 3,2 do $11 \%$. Prema pojednostavljenom sPESI skoru klasa III,IV i $\mathrm{V}$ imaju $>1$ boda i mortalitet se kreće oko 10,9\%. 
Dok mali rizik obuhvata grupu PESI klasa I ( mortaliteta $0-1,6 \%$ ) i klasa II (mortaliteta $1,7-3,5 \%$ ) ili pojednostavljen sPESI sa 0 bodova i 30 dnevnom smrtnosću od 1\% (tabela 1) $(2,3)$.

Tabela 1. Originalni i pojednostavljeni indeks težine plućne tromboembolije (PESI i SPESI). SpO2 - saturacija hemoglobina kiseonikom.

\begin{tabular}{|l|l|l|}
\hline Kriterijum & PESI & sPESI \\
\hline Životna dob & Godine & $>80$ godina 1 \\
\hline Muški pol & 10 & 1 \\
\hline Karcinom & 30 & \\
\hline Srčana slabost & 10 & Hronična kardiorespiratorna bolest 1 \\
\hline Hronična plućna bolest & 10 & \\
\hline Srčana frekvenca $\geq 110 / \mathrm{min}$ & 20 & 1 \\
\hline Sistolni krvni pritisak $<100 \mathrm{mmHg}$ & 30 & 1 \\
\hline Respiracije $\geq 30 / \mathrm{min}$ & 20 & \\
\hline Temperatura $<36 \mathrm{C}$ & 20 & \\
\hline Izmenjen mentalni status & 60 & \\
\hline SpO2 $<90 \%$ & 20 & 1 \\
\hline Rizik od ranog mortaliteta & $\begin{array}{l}\text { I } \leq 65 \text { veoma nizak rizik }(0-1,6 \%) \\
\text { II } 66-85 \text { nizak rizik }(1,7-3,5 \%)\end{array}$ & 0 nizak rizik $(0-2,1 \%)$ \\
& $\begin{array}{l}\text { III } 86-105 \text { umeren rizik }(3,2-7,1 \%) \\
\text { IV 106-125 visok rizik }(4-11,4 \%)\end{array}$ & \\
& V $\geq 125$ veoma visok rizik $(10-24,5 \%)$ & \\
\hline
\end{tabular}

U tabeli 2 prikazana je stratifikacija bolesnika prema težini bolesti i mortalitetu, na visok rizik od mortalitet. Bolesnici koji su hemodinamski nestabilni leče se sa fibrinolitičkom terapijom ili embolektomijom, lokalnom lizom ili mehaničkiom aspiracijom. U tu grupu spada oko $10 \%$ bolesnika.
Umereno visok rizik za mortalitet se deli na visok i mali, njih oko $67 \%$ koji se leče pretežno sa nefrakcionisanim heparinom ili LMWH ukoliko je srednje-nizak rizik, a ovi sa malim rizikom za mortalitet njih oko $20 \%$ su kandidati za ambulantno lečenje ili rano otpuštanje (2).

Tabela 2. Stratifikacija plućne tromboembolije prema riziku od ranog mortaliteta. DK-desna komora.

\begin{tabular}{|c|c|c|c|c|c|}
\hline \multirow{2}{*}{\multicolumn{2}{|c|}{$\begin{array}{l}\text { Rizik od ranog } \\
\text { mortaliteta }\end{array}$}} & \multicolumn{4}{|c|}{ Faktori rizika i skorovi } \\
\hline & & \multirow{2}{*}{$\begin{array}{ll}\begin{array}{l}\text { Sok } \\
\text { hipotenzija }\end{array} & \text { ili } \\
+ & \end{array}$} & $\begin{array}{l}\text { PESI klasa III-V ili } \\
\text { sPESI } \geq 1\end{array}$ & $\begin{array}{l}\text { Znaci disfunkcije } \\
\text { imidžing testovima }\end{array}$ & $\begin{array}{l}\text { Kardijalni laboratorijski } \\
\text { biomarkeri }\end{array}$ \\
\hline Visok & & & $(+)$ & + & $(+)$ \\
\hline \multirow{2}{*}{ Srednji } & Srednje visok & - & + & \multicolumn{2}{|l|}{+} \\
\hline & Srednje nizak & - & + & \multicolumn{2}{|l|}{ Bilo koji ili nijedan pozitivan } \\
\hline \multicolumn{2}{|l|}{ Nizak } & - & - & \multicolumn{2}{|c|}{ Procena po izboru, ako se oba procenjuju, oba negativna } \\
\hline
\end{tabular}

Prema Britanskom torakalnom udruženju (British thoracic society, BTS) od 2018 g. uključujući kriteriji za ambulantno lečenje su bolesnici sa plućnom tromboembolijom PESI klasa I i II ili pojednostavljen sPESIsa 0 bodova (3). Procenom Hestia kriterijumima, za lečenje bolesnika u ambulantnim uslovima isključuju bolesnike koji su hemodinamski nestabilni, koji imaju ubrzanu srčanu frekvencu $>110 /$ min i nizak sistolni pritisak $<100 \mathrm{mmHg}$, te nisku saturaciju hemoglobina kiseonikom $<90 \%$ duže od 24 časa. Ovi bolesnici imaju indikaciju za hospitalizaciju primenu inotropa i trombolizu u jedinici intenzivne nege, ili embolektomiju. Ambulantni tretman se ne može sprovoditi kod aktivnog krvarenja ili rizika od velikog krvarenja (nedavno gastrointestinalno krvarenje unutar 14 dana, nedavna oparacija, cerebrovaskularni inzult unutar 10 dana, maligna hipertenzija, trombociti manji od $75000 / \mathrm{mm}^{3}$ ). Za procenu rizika od krvarenja koristimo HASBLED skor (tabela 3) (2). 
Tabela 3. HASBLES skor. SAP - srednji arterijski pritisak, AST - aspartat aminotransferaza, ALT - alanin aminotransferaza, AP - alkalna fosfataza, INR - internaiconalni normalizovani odnos za protrombinsko vreme, NSAIL - nesteroidni antiinflamatorni lekovi.

\begin{tabular}{|l|l|}
\hline Kriterijumi & Bodovi \\
\hline Arterijska hipertenzija (nekontrolisana ili SAP $>160 \mathrm{mmHg}$ ) & 1 \\
\hline $\begin{array}{l}\text { Patološke vrednosti parametara jetrene ili bubrežne funkcije (ciroza, bilirubin }>2 \mathrm{x} \text { i AST/ALT/AP }>3 \mathrm{x} ; \text { dijaliza, } \\
\text { transplantat, kreatinin }>200 \mu \mathrm{mol} / \mathrm{l} \text {; za svako po } 1 \text { bod) }\end{array}$ & $1-2$ \\
\hline Cerebrovaskularni inzult & 1 \\
\hline Krvarenje (prethodno major krvarenje ili predispozicija za krvarenje) & 1 \\
\hline Labilan INR (nestabilan/visok INR, INR <60\% vremena je u terapijskom opsegu) & 1 \\
\hline$>65$ godina & 1 \\
\hline Lekovi ili alkohol (aspirin, klopidogrel, NSAIL; $\geq 8$ pića/nedelja; za svako po 1 bod) & $1-2$ \\
\hline $\begin{array}{l}0-2 \text { mali rizik od major krvarenja } \\
\geq 3 \text { veliki rizik od major krvarenja }\end{array}$ & \\
\hline
\end{tabular}

U retrospektivnoj analize 223 bolesnika sa PE i 314 sa dubokom venskom trombozom (DVT) koji su bili na antikoagulantnoj terapiji od 2006 do 2007 g. HASBLED skor je bio korišten u toku 180 dana. Kumulativna incidenca velikog krvarenja je bila $1,3 \%$ u grupi bolesnika bez rizika od krvarenja (HASBLAD manji od 3); i 9,9\% u grupi sa visokim rizikom od krvarenja prema (HASBLAD skor veći od 3) $(5,6)$. Bolesnici koji imaju jak bol i potrebu za opijatima, nisu kandidati za ambulantni tretman. Nisu kandidati ni oni koji imaju komorbiditete koji zahtevaju praćenje stanja i laboratorijske pretrage, kao što su hronična bubrežna insuficijencija sa klirenskom kreatinina $<30 \mathrm{ml} / \mathrm{min}$, izražena jetrena insuficijencija, jer ti bolesnici imaju sklonost ka krvarenju. Bolesnici koji su imali heparinom indukovanu trombocitopeniju (HIT) unutar proteklih godinu dana ne mogu se ambulantno tretirati. Ako bolesnici nemaju alternativu za heparinsku terapiju, indikovana je hospitalizacija. Ako je bolesnik pod oralnom antikoagulantom terpaijom (OAKT) i ima vrednost internaiconalnog normalizovnaog odnosa za protrombinsko vreme (international normalized ratio, INR) jednak ili veći od 2, a dobio je recidiv VTE takođe mora da se hospitalizuje. Morbidna gojaznost (BMI $\geq 35$ ) je rizik za ambulantno lečenje. Socijalni momenat utiče na hospitalizaciju. Ako bolesnik nema mogućnost nege u kućnim uslovima, ako je bez telefonske komunikacije i mejl adrese, bez adherence i komplijanse za lekove, neophodna je hospitalizacija (3).

U tabeli 4 prikazani su Hestia kriterijumi. Kod bolesnika sa sPESI skorom 0, rizik od krvarenja nije potrebno procenjivati (stepen preporuke B). Merenje odnosa desne i leve komore na kompjuterizovanoj tomografiji (CT) i ehokardiografski pregled nisu neophodni ( stepen preporuke C). Kada je proširenje desne komore (identifikovano CT-om ili ehokardiografijom) kod bolesnika koji su pogodni za ambulantno lečenje treba razmotriti merenje Btipa natriuretskog peptida (BNP), N završni prohormona B-tipa natriuretskog peptida (NTproBNP), visokosenzitivni troponin I ili T (hsTnI ili hsTnT). Normalna vrednost može biti korištena kod identifikacije bolesnika sa malim rizikom i takve bolesnike možemo tretirati ambulantno (3). Elevacija ovih biomarkera treba uticati na hospitalizaciju i promptno praćenje ovih bolesnik (stepen preporuke C). Ako je samo jedan od Hestia kriteria pozitivan ambulantno lečenje nije moguće.

Tabela 4. Hestia kriterijumi. SpO2 - saturacija hemoglobina kiseonikom.

\begin{tabular}{|l|l|l|}
\hline Kriterijum & Da / ne & Lečenje \\
\hline Da li je bolesnik hemodinamski nestabilan? & $\mathrm{Da} / \mathrm{ne}$ & 0 da - vanbolničko \\
\hline Da li su tromboliza ili embolektomija neophodne? & $\mathrm{Da} / \mathrm{ne}$ \\
\hline Da li postoji aktivno krvarenje ili visok rizik od krvarenja? & $\mathrm{Da} / \mathrm{ne}$ \\
\hline Da li je potrebna oksigenoterapija duže od 24 h da bi se održala SpO2 $>90 \% ?$ bolničko \\
\hline Da li je PE dijagnostikovana tokom primene antikoagulantne terapije? & $\mathrm{Da} / \mathrm{ne}$ \\
\hline Da li postoji jak bol koji zahteva intravensku primenu analgetika $>24 \mathrm{~h} ?$ & $\mathrm{Da} / \mathrm{ne}$ \\
\hline Da li postoje medicinski ili socijalni razlozi za lečenje u bolnici $>24 \mathrm{~h} ?$ & $\mathrm{Da} / \mathrm{ne}$ \\
\hline Da li bolesnik ima klirens kreatinina $<30 \mathrm{ml} /$ min? & $\mathrm{Da} / \mathrm{ne}$ \\
\hline Da li bolesnik ima tešku jetrenu disfunkciju? & $\mathrm{Da} / \mathrm{ne}$ \\
\hline
\end{tabular}




\begin{tabular}{|l|l|l|}
\hline Da li je bolesnica trudna? & $\mathrm{Da} / \mathrm{ne}$ & \\
\hline Da li je bolesnik imao HIT? & $\mathrm{Da} / \mathrm{ne}$ & \\
\hline
\end{tabular}

Shema 1. Algoritam za procenu rizika od ranog mortaliteta kod bolesnika sa potvrđenom plućnom tromboembolijom $i$ odabir terapije. $R V$-desna komora (right ventricle). AK-antikoagulantna terapija. ICU-odeljenje intenzivne neze

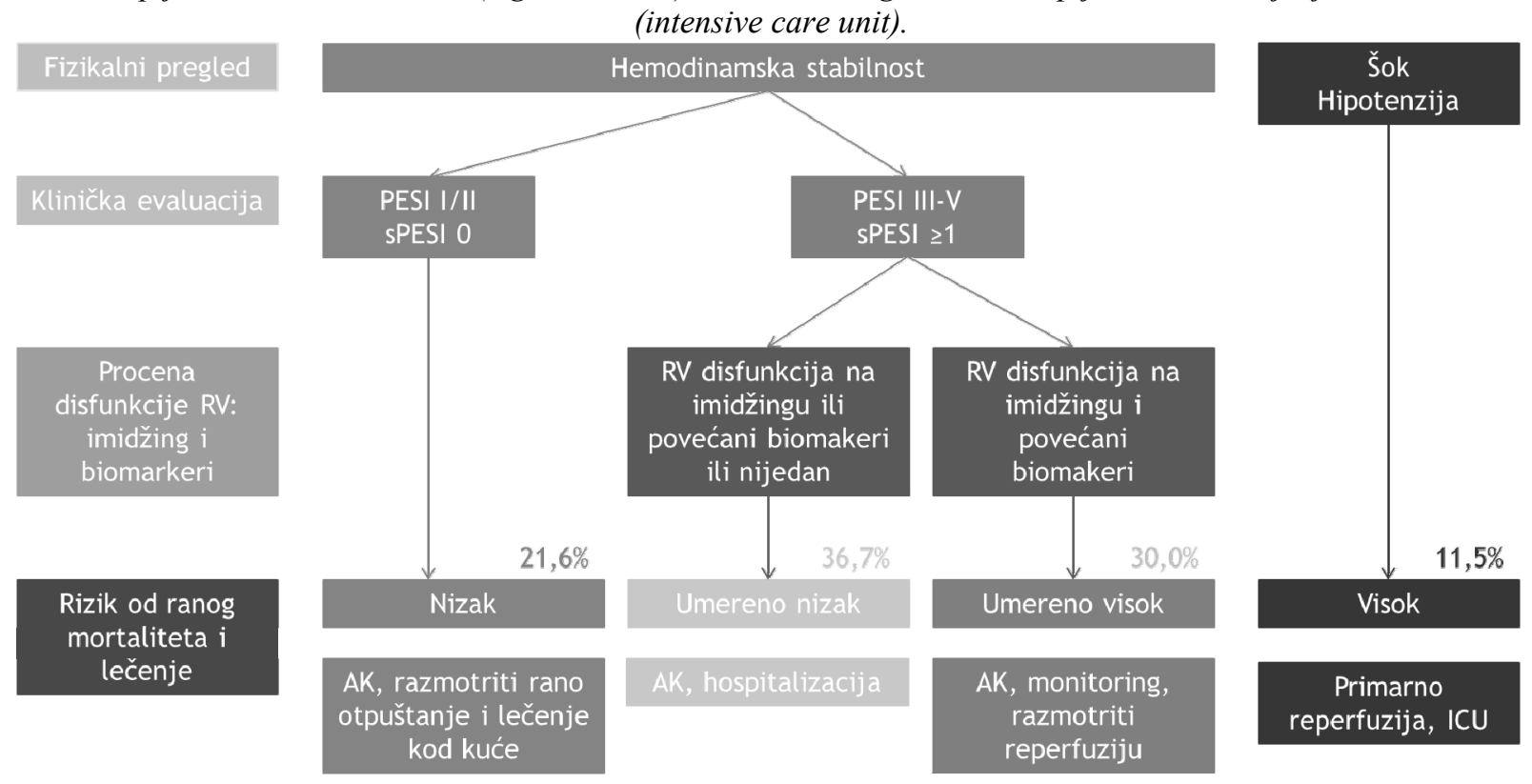

Đ

$\mathrm{Na}$ shemi 1 je prikazan algoritam lečenja bolesnika sa plućnom tromboembolijom (3).

Bolesnici sa PESI I i II ili sPESI se mogu observirati 24 časa u bolničkim uslovima ili sa potvrđenom PE lečenje se preporučuje sprovoditi ambulantno niskomolekularnim heparinom (low molecular weight heparin, LMWH) i dabigatranom, LMWH i edoksabanom, samo direktnim oralnim antikoagulansima (DOAK) apiksabanom ili rivaroksabanom ili LMWH i antagonistima vitamina $\mathrm{K}$ (stepen preporuke A) $(7,8)$. Ambulantno se mogu lečiti i bolesnici sa PE kao posledice maligniteta, atrijalne fibrilacije i srčane insuficijencije kod kojih je slučajno dijagnostikovana PE. Kod maligniteta se slučajno otkrije PE u sklopu praćenja efekta hemio-, radioterapije ili biološke terapije. Ambulantno lečenje PE smanjuje mogućnost infekcije, troškove lečenja i poboljšava kvalitet života. U preporukama stoji da bi lekari seniori, koji imaju veliko iskustvo trebali učestvovati u selekcij bolesnika za ambualntni tretman.

\section{Naša iskustva u ambulantnom lečenju plućne tromboembolije}

U Institutu za plućne bolesti Vojvodineu sklopu Odjeljnja za plućne tromboembolije postoji Ambulanta za prevenciju tromboze. Svake godine je broj bolesnika koji zatraži pomoć u ovoj ambulanti sve veći. Poslednjih godina taj broj je iznosio prosečno 1200 pregleda. To su bolesnici koje pratimo nakon hospitalnog lečenja, prati se terapija i traga za uzrokom venskog tromboembolizma (VTE) ako za vreme hospitalizacije nismo otkrili uzrok. S obzirom da je malignitet često udružen sa VTE povećava se broj bolesnika kojima se u toku praćenja osnovne bolesti slučajno otkrije VTE. Takve bolesnike lečimo ambulantno niskomolekularnim heparinom. Na godišnjem nivou imamo prosečno 150 bolesnika sa slučajno otkrivenim VTE i malignitetom, sa tendencom rasta. Incidenca VTE kod maligniteta raste zbog primene hemioterapije, radioterapije, kao i biološke terapije, jer svi ovi modaliteti lečenja imaju trombogeno dejstvo. I operativni zahvat kod maligniteta može uzrokovati nastanak VTE. Neretko PE može proći asimptomatski ili sa blagim simptomima, stoga je 
važno voditi rčuna o riziko faktorima koji su brojni i koji mogu uticati na nastanak VTE, riziko faktori nam mogu pomoći u dijagnostici VTE. Bitna je prevencija u hirurgiji, pri laparaskopskim operacijama, dijagnostičkim procedurama, naročito kod bolesnika koji su imali VTE ili imaju urođenu ili stečenu trombofiliju.

Široku primenu u našoj zemlji su našli direktni oralni antikoagulansi (DOAK), koji deluju direktno na trombin ili na Xa faktor. Prema prporukama BTS, ako bolesnici imaju 0 bodova prema sPESI skoru mogu se lečiti sa apiksabanom ili rivaroksabanom od prvog dana nastanka VTE ambualntno. Procenu pravimo uz pomoć isključujućih Hestia kriterijuma, ako je skor 0 možemo se odlučiti za ambulantni tretman. Međutim, problem je što bi lekar koji vodi takvog bolesnika morao u svakom trenutku biti dostupan svom bolesniku, što u našim uslovima nije moguće. Drugi problem je što apiksaban i rivaroksaban $u$ našoj zemlji nemaju antidot, a $\mathrm{i} u$ razvijenim zemljama je antidot preskup i nije lako dostupan. Mišljenja smo da je potrebna dobra procena bolesnika za ambulantni tretman, iskusnog lekara, značajno je i ako se desi letalan ishod u $1 \%$ slučajeva zbog VTE u toku 30 dana, a u hospitalnim uslovima se možda mogao sprečiti letalan ishod.

\section{Zaključak}

Bolesnici koji su stratifikovani prema PESI I i II ili sPESI 0 su kandidati za ambulantno lečenje. Hestija kritriji su važni kao isključujući kriteriji za ambulantni tretman bolesnika saPE. Važno je uključiti iskusne lekare u proceni ovih bolesnika na osnovu kliničke slike preporučenih skorova, te primene laboratorijskih nalaza kao i imidžing metoda da donose odluku o ambulantnom ili hospitalnom lečenju VTE. Preporuke su da ovakve bolesnike možemo observirati $24 \mathrm{~h}$, a nakon toga otpustiti uz adekvatnu terapiju, uz kontinuiran telefonski kontakt bolesnik-lekar, ako bolesnici imaju dobru socio-epidemiološku potporu, ali ako su bez adherence i komplijanse za lekove, nisu pogodni za ambulantno lečenje. Ambulantno lečenje PE smanjuje mogućnost infekcije, troškove lečenja i poboljšava kvalitet života bolesnika.

\section{Literatura}

1. Cohen at all. Venous thromboembolismin Europe. The number of VTE events and associated morbidity and mortality. Thromb Haemost, 2007;98(4)756-765

2. Konstantinidis SV. Et all. 2014 ESC guidelines on dianosis and managment of acute pulmonary embolism, Eur Heart J. 2014 Nov 14;35(43):303369, 3069a-3069k.

3. Luke S G E Howard, and all: British Thoracic Society Guideline for the initial outpatient managment of pulmonary embolism, Thorax 2018; $1-29$

4. Tobias Tritschler and all Venous Thromboembolism, Advances in Diagnosis and Treatment, JAMA Octobr 16. 2018, Volume 320, Number 15, 1583 1592

5. Jimenez D. And allč Prognostic models for selecting patients with acutw pulmonary embolism for initial outpatient therapz Chest 2007; 132:4-30

6. Kabrhel C. And all Factors associated with clinical deterioration shortly after PE.Thorax 2014;69:83542

7. NICE. Venous thromboembolc diseases; the menagment of venous thromboembolic diseases and role of thrombophilia testing, 2012.CG144 2012.

8. Kearon $\mathrm{C}$ and al. Antithrombotic Therapy for VTE Disease: CHEST guideline and expert panel report. Chest 2016; 149:315-52

9. Zondag W, and al. Outpatient versus inpatient treatment in patient with pulmonary thromboembolism: meta analysis.Eur Respir J 2013; 42:134-44.

10. Piran S and al. Outpatient treatment of symptomatic pulmonary embolism: a systematic review and meta analysis. Thromb Res 2013; 132:515-9.

11. Vučićević Trobok J. Dijagnostika i lečenje plućne tromboembolije, Monografija, Medicinski fakultet Univerzitet u Novom Sadu, 2013.

\footnotetext{
Abstract

Pulmonary embolism (PE) has been stratified, according to the pulmonary embolism severity index (PESI) or the modified and simplified PESI-sPESI related mortality risk, as a low, intermediate and high, or as a low and high mortality risk respectively. The patients with SPESI score related low mortality risk are candidates for outpatient treatment. The 2014 recommendations of the European Society of Cardiology (ESC) suggested the PESI score related classification of PE patients into five
} 
categories. According to the SPESI score, the PE patients with a high mortality risk (PESI categories $I I I, I V$ and $V$ ) ie. patients with $S P E S I>1$ and the mortality around $10.9 \%$, and the low mortality risk class of PE patients includes the PESI categories I and II, or the patients with the 0 simplified sPESI score and the $1 \%$ mortality in 30 days.

According to the British Thoracic Society (BTS) recommendations of 2018, the candidates for outpatient PE treatment are the patients classified into PESI classes I and II, or with the sPESI 0 score, or those with the Hestia criteria 0. Comorbidities play an important role in evaluating the possibility for outpatient treatment of PE. It is abandoned if a patient is assessed to have the risk of bleeding. Social conditions (no conditions for home care, no telephone, no drug adherence and compliance) also unable a save home treatment. The risk of bleeding need not be assessed inpatients with sPESI 0 score (grade B recommendation).

PE patients who are candidates for outpatient treatment may be observed for 24 hours in hospital conditions and then discharged. The recommended home treatment should be performed with low molecular weight heparin (LMWH) and dabigatran, LMWH and edoxaban, or direct oral anticoagulants (DOAC) only apixaban or rivaroxaban (grade A recommendation) or LMWH $i$ vitamin $K$ antagonists. The outpatient treatment is also possible inpatients whose PE is due to a malignancy, AF or cardiac insufficiency with accidentally diagnosed PE. PE is accidentally discovered in patients with a malignancy in the course of chemo, radio or biological treatment effects assessment. The outpatient PE treatment reduces the risk of infections and treatment costs, and improves the quality of life.

Key words: pulmonary thromboembolism, PESI scor, sPESI scor, outpatient traetmant, LMWH, $D O A C$

Kontakt autor

Prim. dr Jadranka VučićevićTrobok

Institut za plućne bolesti Vojvodine,

Klinika za urgentnu pulmologiju,

Put doktora Goldmana 4,

21204 Sremska Kamenica, R. Srbija

E-mail: jadarankavt@gmail.com

Telefon: 0214805179 